\title{
A Brief Analysis of the Reference Significance of "Calendar Painting" to Modern Poster Advertisement
}

\author{
Yuwan Ma*1
}

\author{
${ }^{1}$ Shanghai University \\ *Corresponding author. Email: 765635115@qq.com
}

\begin{abstract}
This refers to the card type of single-page calendar, the calendar painting in Chinese folk, also known as the calendar, is China's unique art style, has been one hundred years of history, in the thirties of the 20th century when its booming, but later as the Anti-Japanese War, its foundering, become a piece of history, even so, the calendar painting for the development of China's advertisement still has a great role in promoting. This paper studies the origin, development and innovation of the calander painting. The combination of calendar and modern poster advertising design aims to find the inheritable and development of calendar poster, and find a new development angle for modern poster advertising design.In the development process of the calendar painting, it has experienced a combination of Chinese and Western culture, localization and other stages. Poster advertising, also known as posters, is a form of outdoor advertising and has a long history. In the design process of modern poster advertising, the layout, color application and theme selection of the calendar painting have inspiration and reference significance to modern poster design.
\end{abstract}

Keywords: Calendar paintings, placard, poster culture

\section{INTRODUCTION}

Under the influence of western culture in modern times, Shanghai has become one of the major cities displaying modern design in China, and modern design has also penetrated into all aspects of society. In today's society with rapid economic and technological development, how to explore history and culture and draw lessons from the excellent parts of history and culture to serve the future has become the focus that needs to be considered now. The history of the development of poster advertising must be the history of the development of the calendar painting. As the earliest commercial poster in China, the success of the calendar painting is not accidental. Although the promotion function of the calendar painting as the advertising picture is no longer used, the artistic charm and rich social connotation contained in the month card are still worth thinking about. In the process of development, both values and aesthetic consciousness conveyed by calendar paintings are the product of cultural exchange and combination between China and the West, which provides a sufficient historical basis for the research and development of modern poster advertising. The development of design is often closely related to the development of society. With the development of social economy and the influx of western ideas in this period, people also have a new demand for experience. The combination of art and commerce in this period formed a common form of advertising.[1]
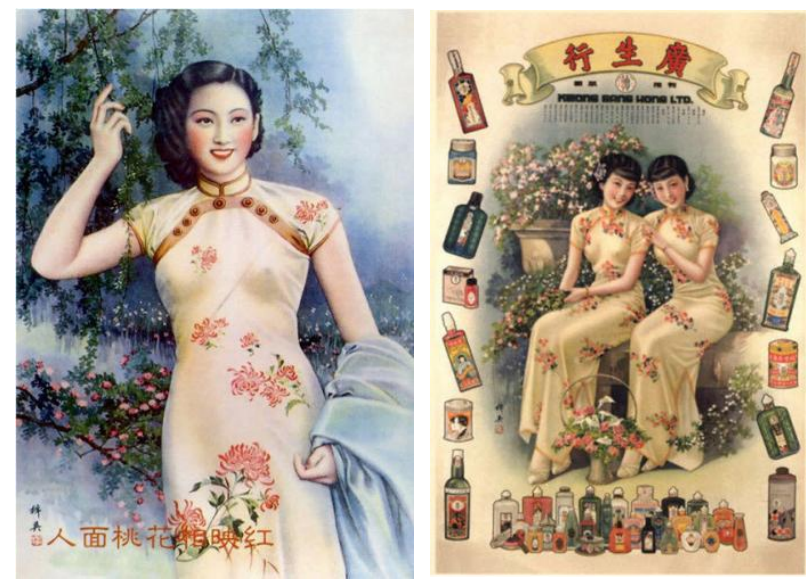

Figure 1 "Hangzhiying" Guangsheng Hong Co., Ltd advertising picture 


\section{THE BIRTH AND DEVELOPMENT OF THE CALENDAR PAINTING}

With the entry of foreign merchants, commercial activities continued to expand, and foreign goods began to be imported rapidly. In order to open the Shanghai market, cigarettes, posters and other promotional materials were introduced together with the goods, which were the earliest Western promotion means introduced. These propaganda paintings are mostly foreign beauties, animals and plants and other patterns, to the people at that time brought a certain amount of sensory stimulation, so that they felt both novel and grotesque. This propaganda does not conform to Chinese people's aesthetics in that time, therefore foreign traders didn't get a bigger development,localization as the Chinese capital after the output mode of advertisements style changes, design combined with local Chinese, closely connected with the mass aesthetic, the calendar painting become a propaganda tool for goods such as foreign goods, it is one of the reasons for the birth of the calendar painting in modern Shanghai.[2]

In the beginning, the calendar painting to traditional Chinese New Year pictures as the main style, the picture content of the Chinese and Western calendar and 24 solar terms as the main, in order to remind farmers production, life. Therefore, this will be with a calendar table in the west of the New Year picture known as "calendar painting". The first advertisement with the word "calendar painting" is the Shanghai Hongfulai ticket in 1896 issued by the Shanghai landscape painting. This period of the calendar painting has begun to have the nature of commercial posters. Although it is called "painting" from the artistic form, but in the perspective of communication, it can already be called "calendar poster advertising" or "calendar advertising picture" and so on. At first, in addition to painting commodities, the theme of Yuejie brand is mostly Chinese traditional landscape, ladies, drama story scenes, etc., and then with the development of economy, in order to meet the aesthetic needs of the Chinese people, the main content of the picture has been formed to show the beauty of fashion.In the form of artistic expression, the creation technique of the calendar painting in the early stage of development is traditional Chinese light color or heavy color, and then in the form of traditional wood-block New Year paintings and calendar painting, painted with meticulous brushwork. Later, it was developed to be expressed in the way of Western brush watercolor. By contrast, the works depicted by this technique are realistic, bright and gorgeous, and full and lifelike. In the function, the month card to make up for the New Year pictures do not have the commercial function, but also for the promotion of goods. Later, with the promotion of foreign cloth, foreign oil and other goods, and give the calendar painting, the calendar painting is loved by the public.[3]

\section{THE CALENDAR PAINTING DEVELOPMENT STAGE CHARACTERISTICS}

With the west wind gradually eastward, the new trend of thought of the fusion of Chinese and western trends of thought has laid a foundation for the development of the calendar painting. Western art forms began to merge with the traditional painting style of the late Qing Dynasty inherent in old Chinese advertisements, and the art form of the calendar painting was gradually unified. The calendar painting in the process of development is not a very clear boundary, more is the state of cultural integration and absorption. In order to better understand the changes in layout and style of the calendar painting, the three major painters of the calendar painting development stage, Wu Jiayou, Zheng Mantuo and Hang Zhiying, are taken as the basis for the development of this period.[4]

\subsection{Wu Jiayou period}

Wu Jiayou (about 1840-1893): Name You, courtesy name Youru. In 1884, he became a major contributor to Dianshizhai Pictorial. He was good at figures of ladies, landscapes, flowers and birds. His painting style close to reality became the image paradigm of Pictorial at that time.Wu Youru's works are greatly influenced by Chen Lao Lian, Gai Qi, Fei Danxu, Ren Xiong, Suzhou New Year Pictures and "mustard garden painting". Therefore, in terms of style, most of Wu's works are drawn by drawing lines first and then setting colors. Wu Youru's calendar painting is full of poetic painting, like a pair of Chinese painting full of lofty artistic conception. Later, with the impact of Western culture, Wu Youru's style was also gradually influenced by Shanghai painters, whose works absorbed the skills of other Shanghai painters such as Ren Bonian. The local Chinese culture did not quit because of the impact of western culture but formed the artistic characteristics of "both Chinese and Western", which is reflected in Wu Youru's paintings, with a fusion of Chinese and Western customs. His works have an obvious "combination of Chinese and Western" style. On the picture, there is not only the form of traditional ink painting with blank space, but also the sense of space before and after the figure with perspective. This combination of Chinese and Western techniques became the main painting method at that time and created the image paradigm of early calendar painting. $\mathrm{Wu}$ Youru strives to break through the traditional and conservative forms of expression in his works. He inherits the woodcut art of Ming and Qing Dynasties and combines it with Western perspective painting. In the subject also seek breakthroughs, such as foreign customs and scenery, high-rise buildings and western ships and trains and other new things. Beside each painting, there will be a paragraph of text explaining the time, place, characters and plots of the work, which is the pioneer of Chinese 
current affairs news genre painting. From the drawing content of the calendar painting, calendar in this period is mainly based on Chinese traditional content, such as folk stories, myths and legends and life scenes, etc., and the layout refers to the folk wood-block prints. Because of the backward technology and other factors, the color of the calendar painting in this period is bright, poor printing. From the advertisement of giving away the calendar board published in Shenbao in 1885, "I have asked Shizhai to print the Chinese and Western calendar boards with white paper. In the middle, the Chinese and Western calendar are combined, and the red characters are used. The green seal on the outer ring is drama 12, which is based on the local Zodiac. The meaning of life is novel, and the painting is exquisite. It's all written by celebrities, and it's hard to put it down." This advertisement illustrates the situation of the calendar at that time.[5]

Although the calendar painting of this period learned from the Western painting methods, integrated perspective, and pursued the real and delicate painting style, but because it was the early stage of the exploration of the calendar painting, the application of Western techniques was still too rigid and immature.

\subsection{Zheng Mantuo period}

Zheng Mantuo had studied the traditional Chinese painting of ladies in Hangzhou Yuying Academy, so his works began to focus on the painting of ladies on the calendar painting. In the continuous practice, Zheng Mantuo explored a series of innovative techniques, and innovated on the theme and layout of the calendar painting, which contributed to the development of the calendar painting in the early 20th century.In the early stage of creation, Zheng Mantuo found that the transition of the traditional painting method was not natural, and the painting was easy to produce brush marks, which affected the overall effect. On this basis, he tried to wipe with pen and scroll on rice paper, which made the picture transition naturally and have a sense of hierarchy. Therefore, he applied this technique to the painting of portraits. The painting method was exquisite and exquisite, which was favored by the public.[6]

Following the introduction of western painting techniques, Zheng Mantuo western realism and the performance of the light and shadow of carbon brush pen painting and Chinese painting techniques, work first by carbon pen wipe light and shade relations of the characters, and then to paint watercolor, the charcoal brush shapes the three-dimensional sense of the person, and the watercolor shapes the texture of the skin. The combination of the two techniques makes the threedimensional sense of the picture stronger, and the characters are delicate and smooth, lifelike, showing the plump and moist temperament of the young woman.Later, Zheng Mantuo was appreciated by Gao
Jianfu, a master of Lingnan School, and he drew a calendar advertising picture for the Shenmei library, which was Zheng Mantuo's first calendar advertising New Year picture Evening Make-up Picture (Figure 2) (published in 1914). The "calendar girl" depicted in this period wore fashionable clothes, but they were not exposed. They still had a subtle and quiet sense of ancient ladies. The faces of the characters are mostly light smiles, and the color is close to the effect of black-and-white photos, so the picture is fresh and natural. Character modeling is mostly reading, viewing and other environments, a change from the previous sketch modeling, showing the characteristics of the transformation of the image paradigm of the calendar painting. The works of this period show a strong combination of Chinese and Western characteristics, in addition to brush watercolor painting techniques, but also learn from Western watercolor painting, photography, oil painting and other art forms, thus forming a new schema language, pushing the development of the calendar painting to another peak.[7]

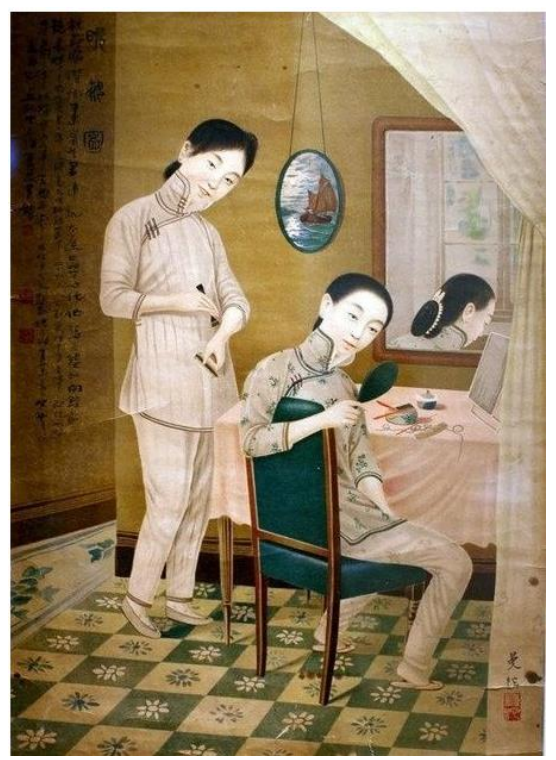

Figure 2 Zheng Mantuo's Evening Makeup Picture

\subsubsection{Innovation of the topic selection and layout of calendar painting}

It seems that Zheng Mantuo has a keen eye for the development of fashion in the future. On the subject matter, zheng mantuo changed the character modeling of ancient dress ladies, but chose fashion and fashionable beauty, and completely abandoned the ancient dress ladies popular in the early republic of China. His works were more in line with the advertising needs of blending Chinese and Western cultures at that time, so they were immediately welcomed by the market. Not only is the subject matter innovative, but Zheng Mantuo is also a person who pays great attention to details. For example, he pays special attention to the clothing of the characters. He immediately applies the most popular shoes and 
jewelry in the season to the picture, giving people a sense of fresh and refreshing experience. However, Zheng mantuo's works were never fabricated by himself, but were created on the basis of in-depth observation of life. For example, in order to create a work, he would choose to observe the passers-by on the most prosperous Nanjing Road at that time. His works are not emotionless and rigid, but full of life and reality. The publicity works on this basis will be easier to obtain the psychological identity and visual experience of the public, thus playing a good role in publicity, which is also the success of Zhengmantuo calendar painting. Zheng Mantuo stands out from the fierce market competition because of his constant exploration and innovation of his works. Follow the needs of the development of The Times, and continue to innovate the theme, so that the works in an invincible position. This is also very worthy of reference in the modern posters.

Zheng Mantuo breaks the traditional layout format of dividing and filling and places the characters and scenes in the works in the center of the picture to highlight the characters' features more easily. Specifically, he adjusted the composition space and layout on the basis of picture segmentation, highlighted the dominant position of people, and paid attention to the balance and blank of picture space. The placement of the goods is flexible and random, and the advertisement of the goods is taken into account while maintaining the artistic sense of the picture, so as not to sacrifice the aesthetic feeling of the whole work for the existence of the goods. Secondly, the treatment of details is also very exquisite, such as the transformation of small objects on the embellishment of characters. Combined with the promotion of goods, adjust the objects held by the characters, and some hold books, fans and other items to coordinate the rich picture. The spatial processing of the picture is also quite exquisite. The processing of the picture is more balanced and hierarchical than before, paying attention to the balance of the whole typesetting. In the past, people were mainly depicted with the front face, but now they are painted alternately with the front face and the side face, it makes the characters more colorful.

\subsection{Hangzhiying period}

Hang Zhiying (1900-1947), who founded Zhiying Painting Studio, was one of the earliest commercial artists in China, mainly engaged in calendar painting design, package design, bill design and trademark design. In the early days, his painting style was mainly based on learning from Zheng Mantuo, and then he tried to figure out the charcoal portraiture on this basis. Hangzhiying's painting style was influenced by many people. He was influenced by German book binders, He Yimei and $\mathrm{Xu}$ Yongqing when he was working in the Commercial Printing Library, which laid the foundation for drawing on Zheng Mantuo's brush erasure painting techniques. At that time, Disney animation had been introduced into China. Hang Zhiying added the color and the sense of the mirror of Disney animation into the calendar painting, thus making the composition of the calendar painting in this period more reasonable and accurate, and the color was more bright, the light and shadow effect was stronger, the style was trendy, and the shape and structure of the characters were more accurate.

\subsubsection{Local innovation of calendar}

Hangzhiying period is the peak of the development of the month brand advertising, this period of the month brand is full of strong localization characteristics. In the topic, Hang zhiying to cheongsam girl this image has carried on the innovation again. Although as early as this period, the dress of the calendar girl has changed from simple to colorful, from robes to tight shorts, the dress is highlighting the beautiful curves of women, but Hangzhiying will have local characteristics of cheongsam and calendar painting combination, leading the social trend.(as shown in figure-3 hang Zhiying's Yindanshilin color cloth calendar "happy lady") During this period, the picture has clear priorities, enlarging the characters, highlighting the theme, and blurry life scenes. The decorative pattern frame of European style is used for reference, and the European architecture or pattern is combined with the image of Chinese women. The color also draws lessons from European and American styles, the overall harmony and unity, reflecting the beauty of the combination of Chinese and Western culture. (as shown in figure-4 "Fushou beer") The layout breaks through the previous rectangular design, which is more diversified. In addition to the common rectangular layout, circular, moonlit and opposite sex are also adopted as the layout center. In the processing of the frame using simplified back grain, geometric grain and European frame as decoration, and even some without the frame, direct drawing on the commodity and trade information, mainly concise. 


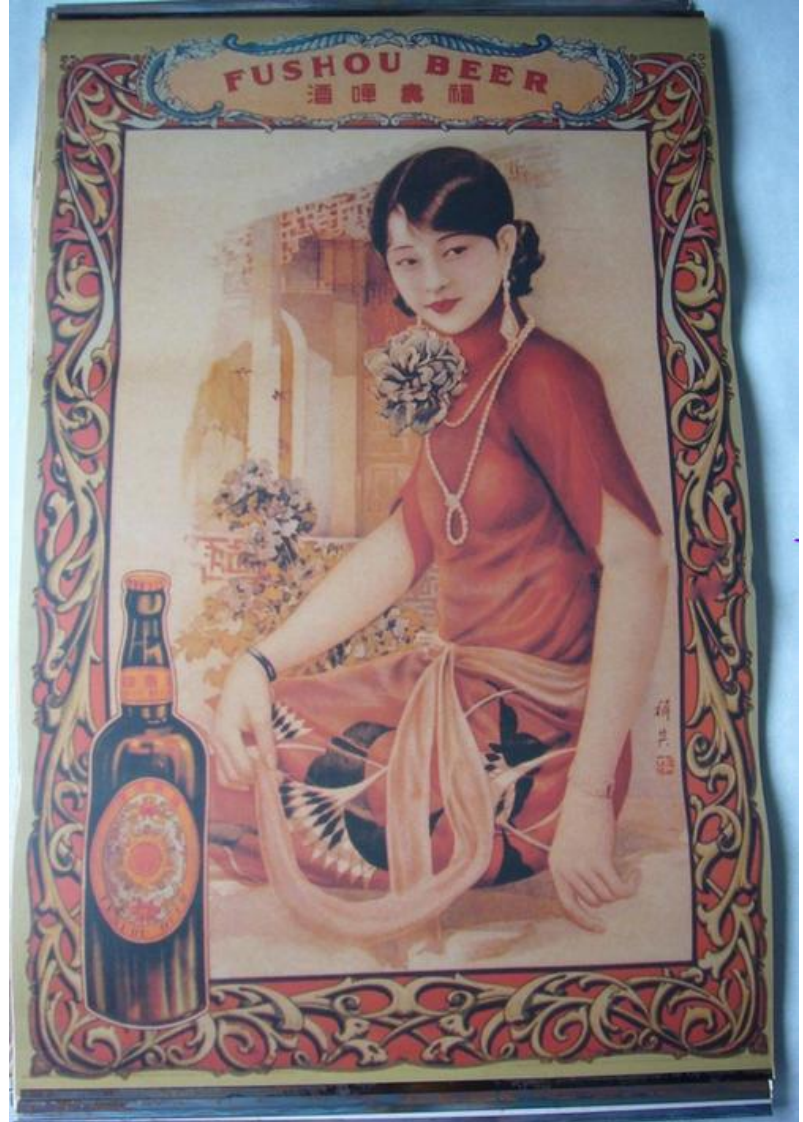

Figure 3 "Fushou beer"

\section{CALENDAR PAINTING IN THE MODERN POSTER ADVERTISING COMMON AND DERIVATIVE}

With the rapid development of society, the calendar painting gradually disappeared in the public's vision, but he played an indelible role in the history. In recent years, with the rise of the national tide, people begin to miss the "old era", but the old era here does not mean that everything in the past is old, but the use of the "old" elements of the past, into a special cultural connotation. For example, the continuation of the excellent traditional patterns in the calendar painting and the use of the design layout of the calendar painting are our next pursuit and exploration goals.

Hangzhou Zhiying's calendar has obvious characteristics of old-fashioned poster advertising. Grape-text combination on the picture, color has reached a more perfect collocation. The combination and separation of elements in the layout and schema are very clever, which reflects the miniature of modern poster advertising. The orderly combination or disassembly of multiple elements and the rational use of schema and layout are used to promote products. Although most of the contemporary posters appear in the form of simple, there is no longer the complex decoration on the calendar painting, but the communication and display of the elements such as words and patterns are essentially the same. As the traditional poster advertising in the calendar advertising can be said to be the predecessor of modern print advertising, so the two exist the same, but different. As a publicity medium, the traditional calendar is used to promote goods, but in the later period, people's attention is focused on the reflection of the characters in the painting. With the development of economic market, advertisement no longer only has the function of conveying information and commodities but has become the means and strategy of competition between enterprises. This change of concept is the key to distinguish traditional and modern poster advertising. The continuation of the use of the calendar painting, let the country wave products to establish a strong "nostalgic" style, and enhance the public's sense of identity to the traditional culture. As shown in Fig. 5, Fig. 6, Fig. 7, Fig. 8 (Red envelope design of baiqueling in 2018). This group of designs extends and adds modern elements to the three themes of the Year of the Dog, the female, and the classic iron can.Baiqueling brand itself is a classic domestic brand with a long history, and its brand tone and calendar coincide. It draws on the rectangular layout design of the calendar and decomposes and combines the elements of the calendar in the work. The color is bright and has a significant atmosphere of the calendar. But different from the calendar, it adopts the flat design which is more suitable for modern posters, and the design of screen materials, characters and fonts is more in line with the aesthetic and trend of modern people. So that the calendar in the form of a continuation of the design has been common.

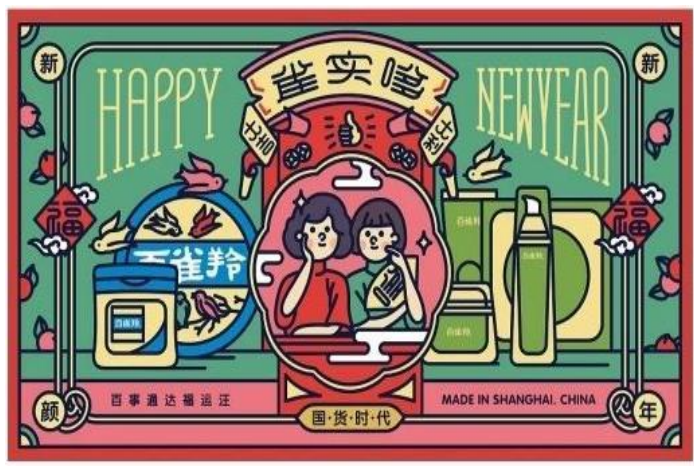

Figure 4 red envelope design of brooding in 2018 


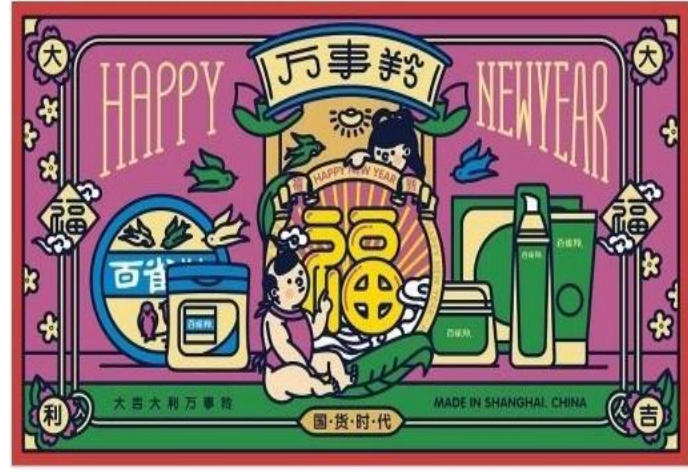

Figure 5 red envelope design of brooding in 2018

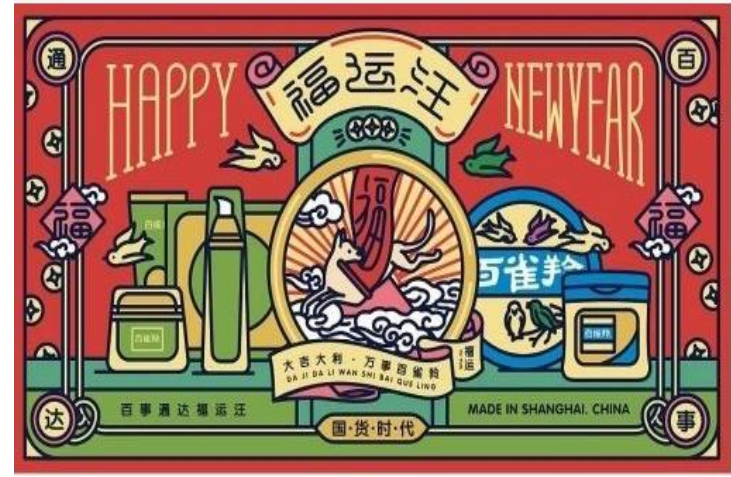

Figure 6 red envelope design of brooding in 2018

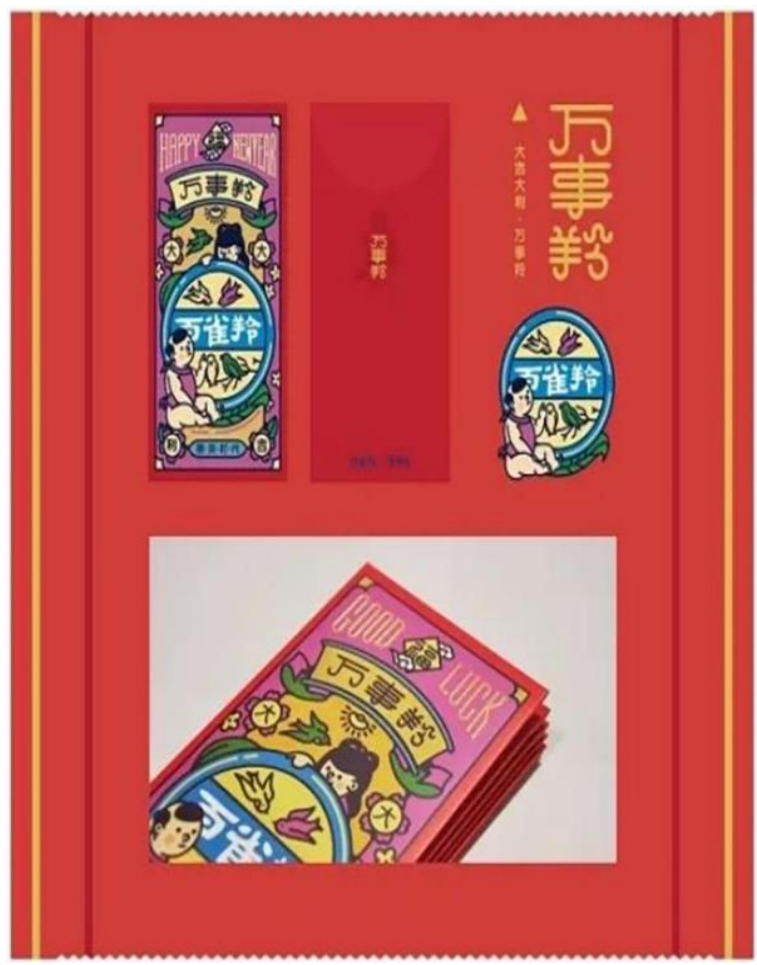

Figure 7 red envelope design of brooding in 2018

\section{CONCLUSION}

The calendar painting advertising is not only the epitome of an era, but also a relatively complete cultural carrier in the Chinese national culture. It not only witnessed the development of modern poster advertising design, but also witnessed the development process of Shanghai in history. It reflected the aesthetic taste and requirements of the public at that time. It was based on popular culture, enjoyed by both refined and popular tastes, and was widely received by the public. In today's global economic and cultural globalization, the advertising industry is booming. As a major form of culture and information dissemination, poster advertising has become an irreplaceable part of the advertising industry. In the contemporary poster advertising, we should pay more attention to the differences between different nations, countries and cultures, and let people remove the barriers between different cultures, regions and races through images and colors, and finally make the poster reach the smooth flow of people's minds through visual schema. This great era characteristic of advertising design, although time in history is not long, but it is the most representative advertising design under Chinese and western cultures, both down in eastern culture, and into the western culture, both traditional aesthetic characteristics, and constantly explore innovative, in line with the social trend to, or even lead the development of the whole social trends. The real advertising design is the integration of cultural exchanges, people-oriented, pay attention to the needs of people, the combination of Chinese and Western, the past for the present, the formation of their own distinctive national characteristics, to continue to inherit the culture of the nation. Therefore, the bright advertising design development under the month card is worth learning from the contemporary poster advertising.

\section{REFERENCES}

[1] Qian Qing. Reviezing the Past, Discussing the Moon Plate and Modern Plane Poster Design [J]. Beauty and Times.

[2] Gong Zhongling. Epoch Characteristics of Poster Advertisement Design [J]. Journal of Hunan University of Science and Technology,2009,30(05):238-239+249.

[3] Cao Pingyuan. On the Art Characteristics of the Design of the calendar Advertising [J]. Research of Fine Arts Education,2013(23):58-64.

[4] Zhang Wei. "Form" and "Color" in Zheng Mantuo and Hang Zhiying Calendar Advertisement Painting [J]. Art and Design (Theory),2014(04):56-58.

[5] Liu Ying, Chen Xinhua. Analysis of the art of the month card $[\mathrm{J}]$. Art and Design (Theory),2007(11):42-44.

[6] Old Yuezhan Brand New Year Pictures [M]. Shanghai Pictorial Publishing House, Deng Ming, 2003

[7] History of Chinese Modern Art Design [M]. Hunan Science and Technology Press, Chen Ruilin, 2002 